\title{
Levantamento de dados com educadores de uma rede privada de ensino: sondagem dos conhecimentos para identificar, intervir e combater o bullying
}

\author{
Data collection with educators of a private teaching network: knowledge survey to identify, \\ intervene and combat bullying
}

Levantamiento de datos con educadores de una red privada del enseñaza: sondeo de los conocimientos para identificar, intervenir, combatir el bullying

Winthney Paula Souza Oliveira ${ }^{1 *}$, Mônica dos Santos de Oliveira ${ }^{1}$, Karla Fernanda Menezes Rodrigues ${ }^{1}$, Amanda Thais Franco Oliveira ${ }^{1}$, Alessandra Serrão Pimenta ${ }^{1}$, Lisiane Costa Bezerra ${ }^{1}$, IIma Costa Rocha ${ }^{1}$, Francisca Tatiana Dourado Gonçalves ${ }^{1}$.

\section{RESUMO}

Objetivo: Verificar os conhecimentos dos professores de uma rede privada de ensino acerca do fenômeno bullying. Métodos: Fizeram parte da pesquisa 09 professores da rede privada de Caxias-MA, exercendo atividade docente no ensino fundamental I e/ou II. Os instrumentos de coleta de dados para a pesquisa foram em forma de questionários sociodemográficos e questionários de conhecimentos específicos sobre bullying. Resultados e Discussões: O bullying é uma realidade de várias instituições escolares, que permeia a instituição privada, e não se restringem apenas ao campo de ensino público. Questionados sobre se já identificaram bullying ao longo da sua trajetória docente e se já interviram em situações de bullying, 08 assinalaram que sim (89\%) e 01 assinalou que não (11\%) em ambos os questionamentos. Quando indagados sobre se achavam que a escola deveria implantar um programa antibullying, 09 responderam que $\operatorname{sim}(100 \%)$. Percebeu-se que os professores apresentam conhecimentos razoáveis relacionados à identificação do bullying, porém esses saberes não se mostram suficientes. Conclusão: Foi percebido que novos saberes sistematizados sejam construídos e buscados. Os docentes precisam aprofundar seus conhecimentos a fim de detectar e intervir em situações de bullying.

Palavras-chave: Bullying, Escola, Docência.

\begin{abstract}
Objective: To verify the knowledge of the teachers of a private teaching network about the bullying phenomenon. Methods: 09 teachers from the private network of Caxias - MA, participated in the study, performing teaching activities in elementary education I and / or II. The data collection instruments for the research were in the form of sociodemographic questionnaires and questionnaires of specific knowledge about bullying. Results and Discussion: Bullying is a reality of several school institutions, which permeates the private institution, and are not restricted to the field of public education. Questioned about whether they have already identified bullying during their teaching career and if they have already intervened in bullying situations, 08 indicated that yes (89\%) and 01 indicated no (11\%) in both questions. When asked if they thought the school should implement an anti-bullying program, 09 said yes (100\%). It was noticed that teachers present reasonable knowledge related to the identification of bullying, but these knowledge's are not enough. Conclusion: It was perceived that new systematized knowledge is built and sought. Teachers need to deepen their knowledge in order to detect and intervene in bullying situations.
\end{abstract}

Key words: Bullying, School, Teaching.

${ }^{1}$ Centro Universitário de Ciências e Tecnologia do Maranhão (UNIFACEMA), Caxias - MA.

*E-mail: winthnew00@hotmail.com

SUBMETIDO EM: 6/2019

ACEITO EM: 7/2019

PUBLICADO EM: 8/2019 


\section{RESUMEN}

Objetivo: Verificar los conocimientos de los profesores de una red privada de enseñanza acerca del fenómeno bullying. Métodos: Fueron parte de la investigación 09 profesores de la red privada de Caxias-Ma, ejerciendo actividad docente en la enseñanza fundamental I y / o II. Los instrumentos de recolección de datos para la investigación fueron en forma de cuestionarios sociodemográficos y cuestionarios de conocimientos específicos sobre bullying. Resultados y Discusiones: El bullying es una realidad de varias instituciones escolares, que permea la institución privada, y no se restringen sólo al campo de enseñanza pública. En el caso de que se hayan identificado bullying a lo largo de su trayectoria docente y si ya intervinieron en situaciones de bullying, 08 señalaron que sí (89\%) y 01 señaló que no (11\%) en ambos cuestionamientos. Cuando se les preguntó sobre si creían que la escuela debía implantar un programa antibullying, 09 respondieron que sí (100\%). Se percibió que los profesores presentan conocimientos razonables relacionados con la identificación del bullying, pero estos saberes no se muestran suficientes. Conclusión: Se percibió que nuevos saberes sistematizados sean construidos y buscados. Los docentes necesitan profundizar sus conocimientos para detectar e intervenir en situaciones de bullying.

Palabras clave: Bullying, Escuela, Docencia.

\section{INTRODUÇÃO}

O índice de violência no espaço escolar vem crescendo no Brasil e tornando-se preocupação social, pois os efeitos danosos na vida dos estudantes vítimas de situações violentas são externados por meio de desestruturação biopsicossocial. Dessa forma, uma instituição com o intuito de educar e proteger tem se constituído atualmente como um espaço de violação dos direitos, marcada por situações de conflitos. As manifestações de violência observadas na escola são de ordem física, verbal, agressões, transgressões às regras, más condutas e relações sociais deturpadas, gerando exclusão neste espaço entre seus agentes participantes (SILVA FR e ASSIS SG, 2018).

Abramovay M e Rua MG (2002) alerta que a escola tem perdido a concepção de espaço seguro em decorrência dos problemas de violência, conflitos, exclusão social e das próprias dificuldades cotidianas.

Para minimizar a ocorrência de agressões escolares é preciso que os profissionais da educação obtenham formação para atuar na prevenção, resolução e combate de conflitos no meio escolar, assim a escola poderá voltar a ser concebida como um espaço de boas relações sociais e proteção de crianças e adolescentes (GIORDAN JP, et al., 2017).

A violência escolar encontra-se diluída em três grandes grupos: violência na escola evidenciada por meio das relações instituídas neste espaço, entre alunos e alunos, professor e aluno; violência da escola, quando o corpo administrativo, pedagógico, docente, discente e demais colaboradores reforçam a exclusão e discriminação e por fim a violência contra a escola, observada por meio de práticas excludentes e de desvalorização em relação aos profissionais da educação ou depredação de prédio, materiais e recursos (GIORDANI JP, et al., 2017).

Santos MM,et al. (2015) apontam que a violência escolar afeta alunos, professores, funcionários e a comunidade. Fragiliza as vítimas deixando-as vulneráveis à depressão, ansiedade, delinquência, ideação suicida, evitação da escola, problemas de saúde físicos, baixa autoestima e queda no rendimento acadêmico.

Fante C (2005) apresenta o termo bullying, palavra de origem inglesa, como condutas hostis e agressivas dentro do espaço escolar, por meio de uma relação desigual de poder, de caráter intencional e repetitiva, causando sofrimento às vítimas, abrangendo desde danos físicos, materiais e morais.

Zequinão MA, et al. (2016) apontam que o bullying acontece em qualquer espaço interno ou nas imediações da escola sobretudo nos momentos de intervalo dos estudantes, na sala de aula, na chegada ou na saída da escola. Existem três tipos de personagens e condutas que permeiam o bullying, as vítimas que sofrem o impacto da violência em suas diversas vertentes; os agressores praticantes das condutas depreciativas e as testemunhas que observam corriqueiramente os atos e por temerem represálias, por receio de se tornarem as próximas vítimas silenciam diante os atos violentos (NETO AL, 2004). 
Nogueira RM (2010), em relação aos agressores, autores do bullying, aponta que estes, sofrem ou sofreram agressões e tendem a perpetuar o ciclo através de práticas violentas com aqueles cujos quais julgam mais indefesos, através de opressão e autoridade reproduzindo um comportamento aprendido.

Para Lopes Neto AA (2009) o autor de bullying é impulsivo e a percepção de si em relação a agressividade é vista com uma qualidade. Para ele é prazeroso e gratificante dominar, coagir e constranger, pois dessa forma se vê como mais forte que o oprimido, manifesta pouca ou nenhuma empatia em relação a vítima.

Fante C (2005) diz que o agressor é popular no meio escolar, em sua maioria são oriundos de família desestruturada com pobreza nos laços e envolvimentos afetivos. As vítimas de bullying apresentam características que as tornam aprisionadas às situações de submissão e hostilidade, seja por conta de aspectos físicos e/ou comportamentais, timidez acentuada, insegurança, sensibilidade ou ansiedade.

Não apresentam habilidades para externar uma reação eficaz ao ponto de interromper e impedir a continuidade das agressões. As vítimas de bullying ao longo do tempo apresentam problemas e dificuldades em relação a aprendizagem, capacidade de concentração reduzida, podendo inclusive levar a evasão escolar. Em casos mais severos, comprometimento da saúde física, emocional, o que pode desencadear, ainda, depressão, doenças psicossomáticas e suicídio (SILVA FR e ASSIS SG, 2018).

O terceiro personagem do bullying, são os espectadores, pessoas que presenciam e calam-se diante das ações. Silva ABB (2010), relata que a omissão contribui para a perpetuação da violência e que os espectadores podem ser classificados em auxiliares, quando hostilizam junto ao agressor as vítimas; incentivadores quando diante das agressões exibem condutas de apoio e incitam a continuidade dos atos; observadores que consistem somente em presenciar ou se afastar durante a violência e por fim os espectadores defensores que agem com o intuito de cessar o ciclo de violência através de suas próprias condutas, com auxílio de adulto ou profissional da escola que possa interromper a violência.

O bullying pode ser observado em todos os níveis de ensino desde a educação infantil até a pósgraduação. No Ensino Superior, o bullying em sua maioria, é consumado através de cobranças psicológicas e desestruturação emocional por conta das exigências e solicitações de produções e trabalhos acadêmicos por parte dos professores e orientadores. Essas situações tendem a prejudicar o desempenho positivo dos estudantes na esfera social e educacional gerando déficits em seu rendimento (GARCIA EMS, et al., 2013).

Bacelar S (2012) aponta que os estudantes universitários apresentam maior capacidade de defesa aos ataques, mas que ainda assim, faz-se necessário um posicionamento institucional de combate, controle e erradicação do bullying no espaço acadêmico. As agressões contra universitários, além do enfoque intelectual podem ser presididas por conta de cor, etnia, religião e poder aquisitivo. Gerando exclusão, sofrimento e prejuízos emocionais, cognitivos e acadêmicos. Seja na educação básica ou no ensino superior o bullying apresenta severos prejuízos e consequências na vida dos personagens, com a finalidade de atuar na prevenção e erradicação do bullying na sociedade brasileira, no ano de 2015 por meio Lei $n^{\circ} 13.185$ surge o Programa de Combate à Intimidação Sistemática. A lei dispõe sobre as formas de violência, medidas preventivas e penalidades para o agressor, a fim de que toda a sociedade possa conhecer e combater 0 bullying. Educação, orientações e informação são peças fundamentais para conhecer e atuar na promoção de espaços sociais saudáveis e não violentos.

Formar cientificamente e moralmente os educandos é missão da escola, a Lei de Diretrizes e Bases da Educação (LDB) em seu artigo 2o reforça o dever da família e do Estado para a formação e desenvolvimento através do "preparo para o exercício da cidadania e sua qualificação para o trabalho." Família, escola e comunidade são parceiros para a potencialização e desenvolvimento dos indivíduos. A escola não deve se limitar somente à transmissão de educação científica e sistematizada, os saberes para uma boa convivência também devem ser aprendidos, aperfeiçoados e disseminados neste espaço. O presente trabalho apresenta como objetivo identificar os conhecimentos docentes e suas ações de combate e prevenção do bullying em uma escola de rede privada de ensino, bem como evidenciar a importância da escola para promoção de uma sociedade mais justa e igualitária, promotora de paz, harmonia e respeito. 


\section{MÉTODOS}

A pesquisa foi aprovada pelo Comitê de Ética em Pesquisa com Seres Humanos do Centro Universitário de Ciências e Tecnologia do Maranhão - UNIFACEMA, CAAE: 10181318.6.0000.8007 e parecer no3.263.709. Todos os participantes da pesquisa aceitaram participar do estudo após esclarecimento e assinatura do Termo de Consentimento Livre e Esclarecido, cumprindo o protocolo de aspectos éticos estabelecidos na resolução 466/12 do Conselho Nacional de Saúde, o anonimato foi garantido, preservando assim cada docente participante do estudo.

Consiste em uma pesquisa de campo de cunho quantitativo com o intuito de verificar os conhecimentos dos professores de uma rede privada de ensino acerca do fenômeno bullying. A pesquisa de campo apresenta essa denominação pelo fato de o pesquisador ir ao espaço natural dos fenômenos para o processo de coleta de dados (ANDRADE MM, 2010).

Os instrumentos de coleta de dados para a pesquisa foram em forma de questionários sociodemográficos e questionários de conhecimentos específicos destacando-se os seguintes eixos: atuação docente em situações de identificação e intervenção, mitos sobre bullying e consequências para as vítimas.

Através das respostas evidenciadas pelos professores foi possível mapear as condutas docentes em relação a prevenção, intervenção e combate ao bullying. Detectar e mapear as necessidades dos professores para atuação ativa e detectar a necessidade de formação continuada para enriquecimento das atividades pedagógicas e de compromisso social primando pelo bem-estar na comunidade escolar.

Os questionários foram respondidos in loco, com horários e dia previamente marcados junto à escola pesquisada. As perguntas fechadas, claras e objetivas possibilitaram que o professor assinalasse a opção condizente à sua prática diária pedagógica e sobre os seus conhecimentos acerca da violência no espaço escolar.

As perguntas do questionário percorriam a temática central com enfoque na atuação docente no processo de identificação, intervenção, consequências sociais e psicológicas, tipos de agressão e necessidade de implantação de programa antibullying na escola.

Andrade MM (2010) ressalta que é fundamental que as perguntas de um questionário estejam bem elaboradas que o sujeito pesquisado possa compreender de forma simples, pois não é possível que informações adicionais sejam evidenciadas, portanto, a elaboração das perguntas deve ser objetiva e direta.

\section{RESULTADOS E DISCUSSÕES}

Fizeram parte da pesquisa 09 professores da rede privada exercendo atividade docente no ensino fundamental I e/ou II. O perfil sociodemográfico dos professores da rede privada constitui-se com média de idade de 34 anos, 44\% dos professores tem de 26 - 35 anos. Os 09 professores são do sexo feminino (100\%). 01 professor possui apenas o ensino superior completo (11\%), 07 possuem pós-graduação/Especialização (78\%) e apenas 01 possui pós-graduação/ Mestrado. O tempo de docência tem maior percentual entre 0-5 anos, com 04 professores, correspondendo a $44 \%$. Quanto as turmas de ensino fundamental que exercem atividade docente, 04 atuam no ensino fundamental I (44\%), 01 no ensino fundamental II (11\%) e 4 atuam no fundamental I e II (44\%) (Tabela 1).

Os professores da rede privada, ao serem questionados sobre se já identificaram bullying ao longo da sua trajetória docente e se já interviram em situações de bullying, 08 assinalaram que sim (89\%) e 01 assinalou que não (11\%) em ambos os questionamentos (Figura 1).

Quando indagados sobre se achavam que a escola deveria implantar um programa antibullying, 09 responderam que $\operatorname{sim}(100 \%)$.

Com o exposto destaca-se a atuação dos professores na identificação e intervenção em casos de bullying. Sendo possível identificar que o bullying é uma realidade de várias instituições escolares, que permeia a instituição privada, e não se restringem apenas ao campo de ensino público. 
Tabela 1 - Dados sociodemográficos referentes aos professores participantes da pesquisa do ensino fundamental da rede privada. Caxias - MA, 2019.

\begin{tabular}{|c|c|c|}
\hline 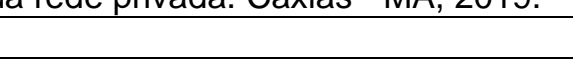 & $\mathbf{N}$ & $\%$ \\
\hline \multicolumn{3}{|l|}{ Idade } \\
\hline $0-25$ anos & 1 & 11 \\
\hline $26-35$ anos & 4 & 44 \\
\hline $36-45$ anos & 2 & 22 \\
\hline 46 ou mais & 2 & 22 \\
\hline \multicolumn{3}{|l|}{ Sexo } \\
\hline Feminino & 9 & 100,0 \\
\hline Masculino & 0 & 0,0 \\
\hline \multicolumn{3}{|l|}{ Escolaridade } \\
\hline Ensino superior completo & 1 & 11,0 \\
\hline Pós-graduação- especialização & 7 & 78,0 \\
\hline Pós-graduação- mestrado & 1 & 11,0 \\
\hline \multicolumn{3}{|l|}{ Tempo de docência } \\
\hline $0-5$ anos & 4 & 44,5 \\
\hline $6-10$ anos & 3 & 33,5 \\
\hline $11-20$ anos & 1 & 11,0 \\
\hline 21 ou mais & 1 & 11,0 \\
\hline \multicolumn{3}{|l|}{ Turma de ensino fundamental } \\
\hline Ensino fundamental 1 & 4 & 44,5 \\
\hline Ensino fundamental 2 & 1 & 11,0 \\
\hline Ensino fundamental 1 e 2 & 4 & 44,5 \\
\hline Total & 9 & 100,0 \\
\hline
\end{tabular}

Fonte: Oliveira WPS, Oliveira MS, Rodrigues KFM, et al., 2019.

Figura 1 - Dados sobre a identificação e intervenção do bullying pelos professores da rede privada e a opinião sobre a implantação do progroma antibullying na escola. Caxias-Ma, 2019.

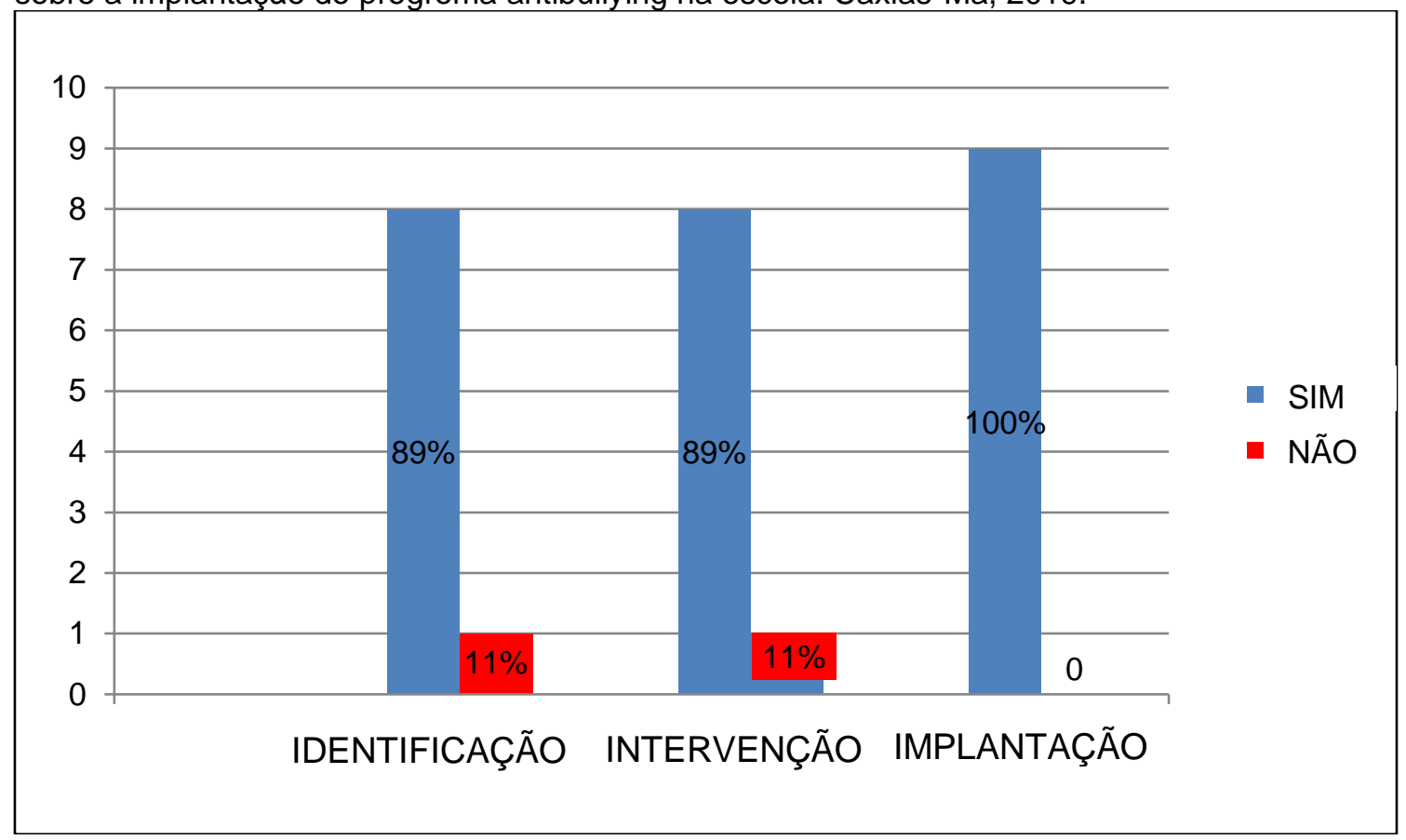

Fonte: Oliveira WPS, Oliveira MS, Rodrigues KFM, et al., 2019.

A atuação do professor na intervenção em casos de bullying é afirmada pela lei no 13 . 474, de 2010, que dispõe em seu Art. $5^{\circ}$ que é dever do estabelecimento de ensino, dos clubes e das agremiações recreativas assegurar medidas de conscientização, prevenção, diagnose e combate à violência e à intimidação sistemática (bullying). 
Sendo importante ressaltar também, o Estatuto da Criança e do Adolescente (ECA), pois o seu Art. 18은 diz que é dever de todos zelarem pela dignidade da criança e do adolescente, pondo-os a salvo de qualquer tratamento desumano, violento, aterrorizante, vexatório ou constrangedor. Dessa forma, é necessário que os professores estejam capacitados para serem ativos em medidas de identificação, intervenção e prevenção do bullying escolar, para assim, estarem colaborando com a proteção e colaborando a promoção da dignidade de crianças e adolescentes.

Ao questionar sobre quais itens julgavam ser consequências às vítimas de bullying, assinalaram as seguintes alternativas, desmotivação para ir ao espaço escolar, $9(100 \%)$, queda no rendimento acadêmico 8 (89\%), evasão escolar $8(89 \%)$, reprovação escolar $4(44 \%)$, ansiedade $8(89 \%)$, fobia escolar $8(89 \%)$, depressão $8(89 \%)$, suicídio $6(67 \%)$, baixa autoestima $8(89 \%)$, estresse $5(56 \%)$, insegurança $8(89 \%)$, são brincadeiras comuns que não geram consequências alguma nos sujeitos, nenhum assinalou essa alternativa (Figura 2).

Pode-se observar que dentre todas as alternativas a reprovação escolar foi a menos considerada dentre todas as outras sugestões. Pesquisas apontam que o insucesso escolar, a reprovação, baixo desempenho e abandono escolar pode ser uma consequência do bullying (Zequinão MA, et al.,2016). O autor Rolim M (2008), aponta que o bullying por se inserir nos relacionamentos entre os alunos, acaba por desperdiçar sua motivação e potencial afetivo, sendo esses fatores muito importantes para o bom desempenho escolar. Com isso fica evidente que a reprovação também, pode ser uma marca do bullying.

Figura 2 - Dados sobre o que os professores da rede privada julgam ser consequências às vítimas de bullying.

Caxias-MA, 2019.

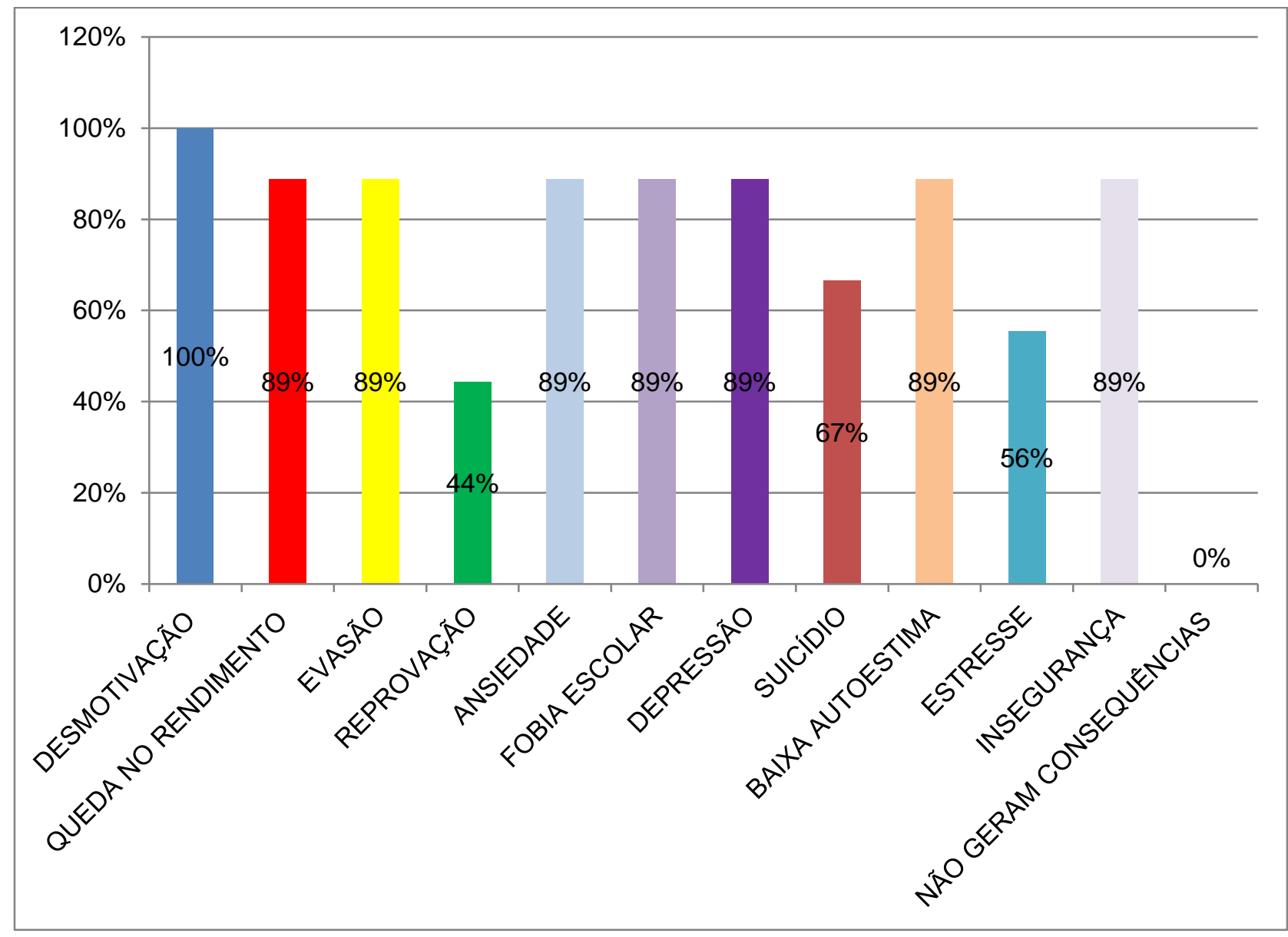

Fonte: Oliveira WPS, Oliveira MS, Rodrigues KFM, et al., 2019. 
Ao questionar sobre os tipos de agressões que o bullying compreende, obteve-se os seguintes resultados, 05 docentes assinalaram agressões físicas (56\%), 07 agressões verbais (78\%), 8 agressões morais e psicológicos (89\%) e 1 agressões sexuais (11\%) (Figura 3).

O bullying se configura em vários tipos de expressão, dentre os que mais se destacam na literatura são, físico, verbal e emocional (SANTOS MAN, 2010; DILLENBURG Al, 2013). Violencias e agressões racistas e indiretas também são compreendidas no espectro do fenômeno. (PEREIRA BO, 2008; ANTUNES DC e ZUIN AAS, 2008; CHALITA G, 2008). Observou-se que a alternativa referente a agressões sexuais foi a menos assinalada, o que ilustra o desconhecimento de alguns professores acerca deste tipo de agressão. Caracterizada nos estudos de Dillenberg AI (2013) a agressão sexual ocorre com mais frequência em crianças mais velhas. Essa prática pode ser considerada assédio sexual e pode causar graves consequências a vítima. Os estudos de Santos MAN (2010) apresentam que o bullying sexual é caracterizado por contato físico indesejado, comentários abusivos, entre outros.

Dessa forma é de grande importância que todos tenham acesso a essas informações, pois como ainda discorre Dillenberg Al (2013) o bullying não pode ser minimizado a um simples conceito de violência. Suas consequências e formas de manifestação são graves e exigem de todos, principalmente dos profissionais da educação, uma atenção especial.

Figura 3 - Dados referente aos conhecimentos dos professores da rede privada sobre os tipos de agressões que o bullying escolar compreende. Caxias-MA, 2019

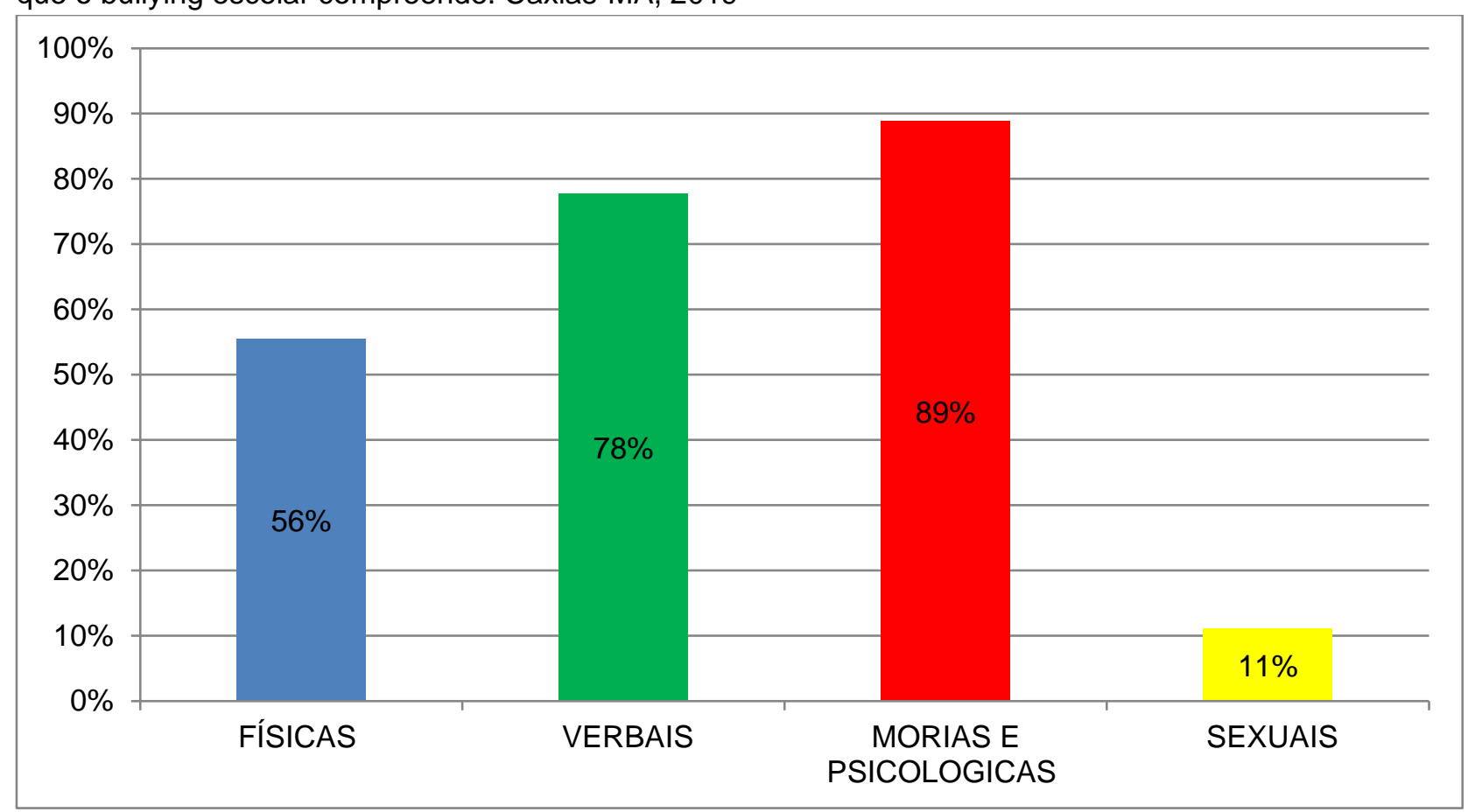

Fonte: Oliveira WPS, Oliveira MS, Rodrigues KFM, et al., 2019.

Os professores foram indagados sobre quais das opções, dentre os mitos e verdades, no seu ponto de vista, constituíam-se como conceito de bullying e sua prática na escola. A Tabela 2 apresenta o percentual das alternativas que foram assinaladas pelos professores da rede privada.

Percebe-se que os professores apresentam conhecimentos razoáveis relacionados à identificação do bullying, porém esses saberes não se mostram suficientes, pois como aponta Dillenburg Al (2013) não é válido um mero diagnóstico, mas faz-se necessário de forma conjunta a resolução dos problemas. Tornandose necessário o reconhecimento concomitante a atuação para a elaboração de procedimentos adequados. 
Tabela 2 - Opções que os professores da rede privada assinalaram como conceito de bullying e sua prática na escola. Caxias - MA, 2019.

\begin{tabular}{lcc}
\hline & $\mathbf{n}$ & $\%$ \\
\hline Acomete somente escola pública e pessoas de baixa renda & 0 & 0 \\
Violência constante, repetitiva e sem motivação aparente & 8 & 89 \\
Uma única agressão externada a um aluno já pode ser considerada bullying & 1 & 11 \\
Acontece mais entre meninos do que meninas & 0 & 0 \\
A manutenção das situações de bullying se deve a incapacidade da vítima de se & 4 & 44 \\
defender dos ataques & \\
Ameaçar & 7 & 78 \\
Amedrontar & 8 & 89 \\
Intimidar & 8 & 89 \\
Bater & 5 & 56 \\
Xingar & 5 & 56 \\
Humilhar & 8 & 89 \\
Acontece em áreas com supervisão adulta & 1 & 11 \\
Bullying é uma coisa passageira, uma bobagem, é tudo brincadeira & 0 & 0 \\
TOTAL & $\mathbf{9}$ & $\mathbf{1 0 0}$ \\
\hline
\end{tabular}

Fonte: Oliveira WPS, Oliveira MS, Rodrigues KFM, et al., 2019.

Os professores foram indagados sobre quais das alternativas apresentadas, acreditavam auxiliar na identificação de que um aluno é alvo de bullying. As alternativas que mais se destacaram como meios de identificação do bullying no espaço escolar assinalado pelos professores foram relacionadas a isolamento, insegurança em sala de aula e busca por está na presença de adultos, observa-se uma visão restrita da maneira de identificação do bullying. O que respalda a necessidade de formações para que os docentes possam atuar de maneira mais ativa no processo de identificação (Tabela 3).

Tabela 3 - Alternativas que os professores da rede privada acreditam que auxiliam na identificação de que um aluno é alvo de bullying. Caxias - MA, 2019.

\begin{tabular}{lll}
\hline & $\mathbf{n}$ & $\%$ \\
\hline Alunos com poucos amigos ou isolados & 7 & 78 \\
Desinteresse pelos estudos & 2 & 22 \\
Insegurança e ansiedade em sala de aula & 7 & 78 \\
Queda no rendimento acadêmico & 5 & 56 \\
Materiais sujos ou rasgados & 4 & 44 \\
Pertences pessoais que "somem" repetidas vezes & 3 & 33 \\
Opta por ficar sempre na presença e companhia de adultos durante o & 7 & 78 \\
recreio escolar & & \\
TOTAL & $\mathbf{9}$ & $\mathbf{1 0 0}$ \\
\hline
\end{tabular}

Fonte: Oliveira WPS, Oliveira MS, Rodrigues KFM, et al., 2019.

A pesquisa consistiu em conhecer as informações que os docentes possuem acerca da prevenção e combate ao bullying, percebeu-se que os docentes precisam aprofundar seus conhecimentos a fim de detectar e intervir em situações de bullying. A escola necessita inserir em sua rotina o cultivo ao respeito e tolerância visando obtenção de um espaço de pleno desenvolvimento pedagógico e social dos estudantes.

O que vem confirmar os estudos de Aguiar LGF e Barrera SD (2017) quando discorrem sobre o fortalecimento das relações entre a escola e os alunos, e um maior preparo dos professores e funcionários para combater todos os tipos de agressão. Sendo considerados pontos extremamente necessários para tentar minimizar os efeitos dos fatores de risco aos quais as crianças estão expostas e, consequentemente, a violência na escola. 
Aos docentes fica a missão de atuar por meio de ações coletivas, fortalecedoras do respeito às diferenças, à diversidade, medidas de combate, prevenção e conscientização sobre o bullying de forma a garantir um ambiente seguro entre os estudantes no espaço escolar, suas ações sistematizadas e embasadas cientificamente são colaboradoras para o processo de erradicação de práticas danosas, suas condutas permitem auxiliar as vítimas para superação dos prejuízos instalados, reconduzir as ações dos espectadores e agressores para que despertem e mudem suas condutas contribuindo para a formação de novas atitudes e valores cidadãos, permitindo que a escola seja um local que vai além da aquisição de conhecimento didático pedagógico, um espaço em que os estudantes se sintam pertencentes, seguros e acolhidos, que possam se relacionar e trocar experiências com respeito, tolerância, inclusão, empatia, sensibilidade, formando alunos de maneira integral, através da interação e socialização. Os educadores atuantes na prevenção e combate ao bullying na escola, em sua prática, devem permitir que os estudantes expressem seus pontos de vista, falem sobre si, suas características, pensamentos sobre família, escola, sobre hábitos de rotina e lazer a fim de possibilitar reflexão sobre o bullying. Despertar mudanças comportamentais positivas em relação ao rompimento de práticas discriminatórias, relacionados a escola e meio social, objetivando propor um enfrentamento eficaz das adversidades e dificuldades oriundas no cotidiano escolar.

\section{CONCLUSÃO}

A pesquisa retrata a grande importância dos profissionais da educação na atuação e combate ao bullying, detectou-se os conhecimentos prévios dos docentes em relação a temática e foi percebido que novos saberes sistematizados sejam construídos e buscados. Observou-se a necessidade que os docentes apresentam de conhecer mais sobre a temática para melhor refletir e atuar diante do bullying, da violência, preconceito, discriminação, consequências, problemas evidenciados e decorrentes do bullying, traçar junto aos alunos estratégias e soluções de superação. Faz-se necessário ainda forma uma parceria entre família e escola para combater agressões, estimular o respeito mútuo, tolerância, empatia e solidariedade, propor discussões críticas e reflexivas, afinal é papel e compromisso social da escola formar cidadãos mais conscientes, éticos, alcançar uma mudança comportamental nos estudantes, disseminar informações acerca dos danos ocasionados em decorrência do bullying bem como combater essa prática entre os estudantes.

\section{REFERÊNCIAS}

1. ABRAMOVAY M, RUA MG. (coord.). Violências nas escolas. Brasília: UNESCO, 2002.

2. ANDRADE MM. Introdução à metodologia do trabalho científico. 10. ed. São Paulo: Atlas.2010.

3. ANTUNES DC, ZUIN AAS. Do bullying ao preconceito: os desafios da barbárie à educação. Psicologia \& Sociedade, v. 20, n. 1, p. 33-42, 2008.

4. AGUIAR LGF, BARRERA SD. Manifestações de bullying em diferentes contextos escolares: um estudo exploratório. Psicologia: Ciência e Profissão, v. 37, n. 3, p. 669-682, 2017.

5. BACELAR S. (Ed). Bullying. Faculdade Integrada da União Educacional do Planalto Central. - Brasília- DF: Faciplac. Stilo Gráfica e Editora Ltda., 2012.

6. BRASIL. Lei nª 13.185, de 06 de novembro de 2015. Programa de Combate à Intimidação Sistemática (Bullying).

7. CHALITA G. Pedagogia da amizade - Bullyng: o sofrimento das vítimas e dos agressores. São Paulo: Editora Gente, 2008.

8. DILLENBURG Al. Gestão escolar e bullying: o contexto da escola privada. 2013.

9. FANTE C. Fenômeno Bullying: Como prevenir a violência nas escolas e educar para a paz. Editora Verus, 2005.

10. GARCIA SEM, VECCHIATTI PRI, MARTA TN. Bullying nas Instituições de Ensino Superior, no 18. Jacarezinho, SP. Programa de Mestrado em Ciências Jurídicas da UENP, 2013.

11. GIORDANI JP, SEFFNER F, DELL'AGLIO DD. Violência escolar: percepções de alunos e professores de uma escola pública. Psicol. Esc. Educ., Maringá, v. 21, n. 1, p. 103-111, Apr. 2017.

12. GOMES LF, SANZOVO NM. Bullying e Prevenção da Violência nas Escolas: Quebrando Mitos, Construindo Verdades. São Paulo: Saraiva, 2013.

13. LOPES NETO AA. Bullying - comportamento agressivo entre estudantes. Jornal de Pediatria. Disponível em: http://www.scielo.br/scielo.php? script=sci_arttext\&pid=S0021-75572005000700006\&lng=pt\&nrm=iso Acesso em 23 mai de 2019. 
14. NETO AL. Diga não ao bullying. 5 ed. Rio de Janeiro, ABRAPIA, 2004.

15. NOGUEIRA RM. A Prática de Violência entre Pares: O Bullying nas Escolas. Revista lberoamericana de Educación.

16. PEREIRA BO. Para uma escola sem violência: estudo e prevenção das práticas agressivas entre crianças. Lisboa: Fundação Calouste Gulbenkian; Fundação para a Ciência e Tecnologia, 2008.

17. ROLIM M. " Bullying": o pesadelo da escola, um estudo de caso e notas sobre o que fazer. 2008.

18. SANTOS MM, PERKOSKI IR, KIENEN N. Bullying: atitudes, consequências e medidas preventivas na percepção de professores e alunos do ensino fundamental. Temas psicol., Ribeirão Preto, v. 23, n. 4, p. 1017-1033, dez. 2015.

19. SANTOS MAN. O impacto do bullying na escola. Porto Alegre: UFRGS, 2010. Trabalho de conclusão de graduação.

20. SILVA ABB. Bullying: justiça nas escolas. Brasília: 2010.

21. SILVA FR, ASSIS SG. Prevenção da violência escolar: uma revisão da literatura. Educ. Pesqui., São Paulo, v. 44, e157305, 2018.

22. ZEQUINAO MA, MEDEIROS P, PEREIRA B et al. Bullying escolar: um fenômeno multifacetado. Educ. Pesqui. São Paulo, v. 42, n. 1, p. 181-198, março de 2016. 